\title{
Minireview
}

\section{Behavioral effects of perinatal opioid exposure}

\author{
Anna Fodor ${ }^{\mathrm{a}, \mathrm{b}}$, Júlia Tímár ${ }^{\mathrm{c}}$, Dóra Zelena ${ }^{\mathrm{a}, *}$ \\ a Institute of Experimental Medicine, Hungarian Academy of Sciences, Budapest, Hungary \\ b János Szentágothai School of Neurosciences, Semmelweis University, Budapest, Hungary \\ c Department of Pharmacology and Pharmacotherapy, Semmelweis University, Budapest, Hungary
}

\section{A R T I C L E I N F O}

\section{Article history:}

Received 8 October 2013

Accepted 5 April 2014

Available online $\mathrm{xxxx}$

\section{Keywords:}

Morphine

Methadone

Pain killer

Street drug

Gender difference

Stress

\begin{abstract}
A B S T R A C T
Opioids are among the world's oldest known drugs used mostly for pain relief, but recreational use is also widespread. A particularly important problem is opioid exposure in females, as their offspring can also be affected. Adverse intrauterine and postnatal environments can affect offspring development and may lead to various disabilities later in life. It is clear that repetitive painful experiences, such as randomly occurring invasive procedures during neonatal intensive care, can permanently alter neuronal and synaptic organization and therefore later behavior. At the same time, analgesic drugs can also be harmful, inducing neuronal apoptosis or withdrawal symptoms in the neonate and behavioral alterations in adulthood. Hence, risk-benefit ratios should be taken into consideration when pain relief is required during pregnancy or in neonates.

Recreational use of opioids can also alter many aspects of life. Intrauterine opioid exposure has many toxic effects, inducing poor pregnancy outcomes due to underdevelopment, but it is believed that later negative consequences are more related to environmental factors such as a chaotic lifestyle and inadequate prenatal care. One of the crucial components is maternal care, which changes profoundly in addicted mothers. In substance-dependent mothers, pre- and postnatal care has special importance, and controlled treatment with a synthetic opioid (e.g., methadone) could be beneficial.

We aimed to summarize and compare human and rodent data, as it is important to close the gap between scientific knowledge and societal policies. Special emphasis is given to gender differences in the sensitivity of offspring to perinatal opioid exposure.
\end{abstract}

(c) 2014 Elsevier Inc. All rights reserved.

\section{Contents}

Introduction $\ldots \ldots \ldots \ldots$

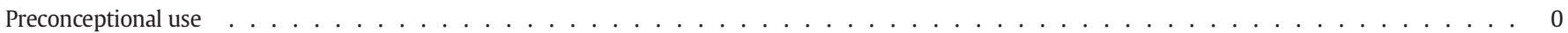

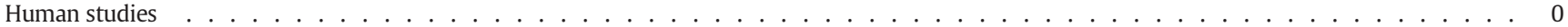

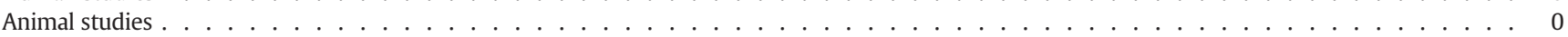

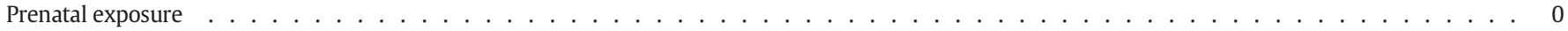

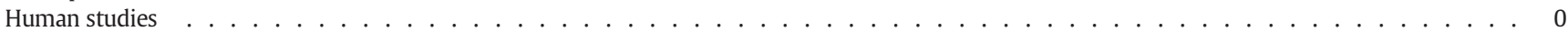

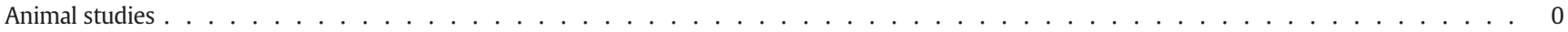

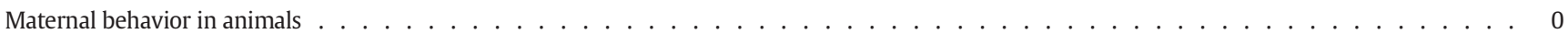

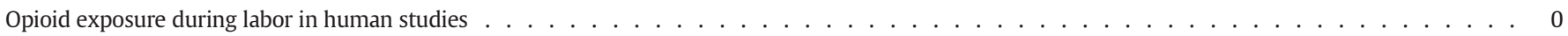

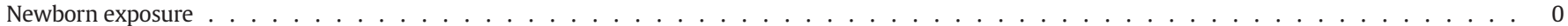

Via the mother . . . . . . . . . . . . . . . . . . . . . . . . . . . . . . . . . . . 0

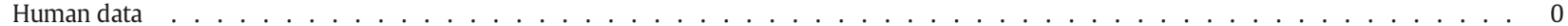

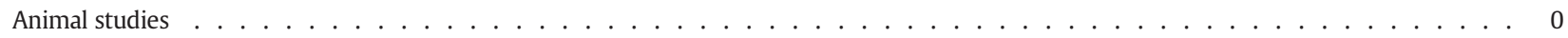

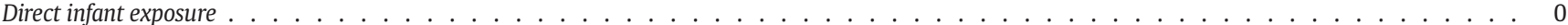

Therapeutic usage in humans . . . . . . . . . . . . . . . . . . . . . . . . . . . . . . . . . . 0

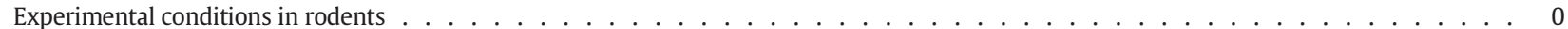

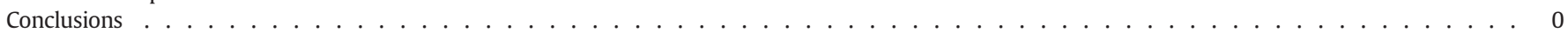

\footnotetext{
* Corresponding author at: Institute of Experimental Medicine, Hungarian Academy of Sciences, 1083 Budapest, Szigony 43, Hungary. Tel.: +3612109400; fax: +36 12109951.

E-mail address: zelena.dora@koki.mta.hu (D. Zelena).
} 


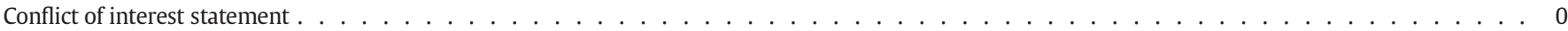

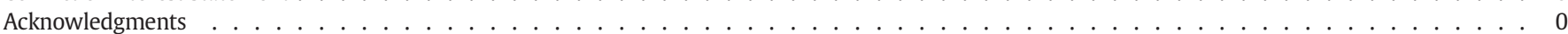

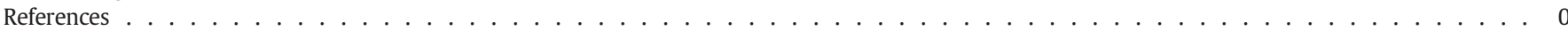

\section{Introduction}

Opiates are drugs derived from opium (e.g., morphine, heroin, codeine), a powdered dried exudate of the fruit capsule (poppy) of the plant Papaver somniferum, that act on opioid receptors in our body. Opioids are among the world's oldest known drugs; archeological evidence and fossilized poppy seeds suggest that Neanderthals may have used these drugs over thirty thousand years ago (Rosenfeld and Loose, 2007). The drugs' main effect is to relieve pain, so they are powerful analgesics. Furthermore, opioids are well known for their ability to produce euphoria, motivating certain individuals to engage in recreational use.

The potential danger of most opioids is that prolonged use results in physical and psychological dependence (Kaltenbach, 1996). According to a study published in The Lancet (Kapp, 2003), heroin is the most dangerous drug among those studied based on its physical harm to the user, addictive potential and overall negative impact on society. In 2010, there were reportedly as many as 2.4 million people in the United States (US) with an opioid problem (Rockville, 2011). However, the majority of opioids used in the US originate from a legal doctor's prescription written to treat pain.

A particularly important problem is the use of opioid drugs (both painkillers and "street drugs") in females, as these drugs may also influence offspring. Similar to many abused drugs, morphine can cross the placenta and blood-brain barrier and even exudes into the breast milk. Opioid receptors are present in several areas of the brain, and multiple mechanisms can be affected by opiate exposure (Yanai et al., 2003). Based on data averaged across 2010 and 2011 in the US, among pregnant women (15-44 years old), 5\% were current illicit drug users (Rockville, 2012). Rats are used extensively to study the developmental effects of opiates because many of their responses to drugs resemble those of humans (Bashore et al., 1981). However, there is a gap between rodent-based scientific knowledge and societal policies (Thompson et al., 2009).

We aimed to review the effect of opioid treatment/use on offspring, comparing human and rodent studies, with the goal of identifying the gaps between the two study types. We follow a "chronological" order, from preconceptional effects to intrauterine treatments and treatments during labor to the early and late consequences of postnatal administration, with special emphasis on possible gender differences.

\section{Preconceptional use}

\section{Human studies}

It is known that preconceptional effects can profoundly alter later pregnancy and the fetus (Twigt et al., 2012). Despite this fact, in humans, the pregnancy rate is not influenced by injection drug (such as heroin) use (Weber et al., 2003). We must mention, however, that low uptake of reliable contraception can confound the results.

\section{Animal studies}

Appropriate usage of morphine can be beneficial in enhancing the pregnancy rate, based on a study using embryo transfer in rats (Smith et al., 2004). In rodents, a premating morphine exposure regimen (prior to pregnancy) had no effect on maternal behavior (Yim et al., 2006; Johnson et al., 2011) but induced long-term effects in offspring. In line with this finding, the female offspring of dams exposed to morphine during puberty displayed increased anxiety-like behavior both in the elevated plus-maze (EPM) and in a novel environment, possibly due to altered prolactin regulation (Byrnes, 2005a). The male offspring of females exposed to morphine during adolescence showed alteration in their early social playing behavior (Johnson et al., 2011). Thus, there is a transgenerational effect of opioid exposure, with gender-specific alterations (Slamberova et al., 2005).

\section{Prenatal exposure}

\section{Human studies}

Among the opioids, heroin, methadone and buprenorphine (the last two are synthetic opioids used as anti-addictive maintenance preparations) are the forms most commonly used by pregnant women (Bhuvaneswar et al., 2008). Opioids undergo rapid transplacental passage (less than $60 \mathrm{~min}$ ), and maternal and fetal withdrawal is likely to begin 6-48 h after the last use (Bhuvaneswar et al., 2008).

Pregnancy complications, including premature rupture of the membranes, meconium-stained liquor and fetal distress, are more common in women who misuse drugs (Johnson et al., 2003). The incidence of stillbirths and neonatal mortality in addicts is 2-4 times higher than that in the general population (Lam et al., 1992). Moreover, sudden infant death syndrome is seven times more frequent in the children of addicts than in the normal population. The principal causes of infant death are prematurity and growth retardation (Bashore et al., 1981). In a Chinese population, babies born to drug-addicted mothers were on average $629 \mathrm{~g}$ lighter at birth, $5 \mathrm{~cm}$ smaller in head circumference and $7 \mathrm{~cm}$ shorter in body length (Lam et al., 1992). Adverse consequences are associated with many incremental social, psychosocial and contextual factors, such as a chaotic lifestyle, incomplete nutrition, intrauterine infections and inadequate prenatal care (Schempf, 2007). In fact, $75 \%$ of pregnant heroin addicts do not receive any prenatal care (Bashore et al., 1981).

Methadone treatment during pregnancy offers overwhelming advantages compared with the less acceptable option of medical detoxification or the unacceptably dangerous option of leaving heroinaddicted women dependent on street drugs (Kandall et al., 1999). The Maternal Opioid Treatment: Human Experimental Research (MOTHER) project found both methadone and buprenorphine to be important parts of a comprehensive treatment approach (Jones et al., 2012a, 2012b). Many studies examining neonatal outcomes among pregnant heroin users treated with methadone have reported improvements in birth weight (Strauss et al., 1974; Kandall et al., 1975). Therefore, methadone treatment has become the 'gold standard' for management of the pregnant heroin user. However, subsequent studies have suggested that heroin use while receiving methadone may counteract the birth weight advantage gained from methadone alone (Hulse et al., 1997), but this phenomenon may be connected to the chaotic and high-risk lifestyle of users as well (Hulse et al., 1998). Further studies are required to identify important factors related to drug use (e.g., social circumstances, poor nutrition, stress, infections). Influencing these factors will be beneficial to improving neonatal outcomes (Schempf, 2007).

Neonatal abstinence syndrome (NAS), or withdrawal symptoms, occur in 55-94\% of neonates exposed to opiates in utero, without a significant difference between male and female infants (Holbrook and Kaltenbach, 2010). Commonly observed symptoms include irritability, high-pitched crying, tremors, hypertonicity, vomiting, diarrhea and tachypnea (Johnson et al., 2003). The onset of signs attributable to neonatal withdrawal from heroin often begins within $24 \mathrm{~h}$ of birth, 
whereas withdrawal from methadone can be delayed. Infants scoring over a certain numerical threshold on abstinence tests are treated with medication (Jansson et al., 2009). The goal of medication therapy is the stabilization of more severely symptomatic infants, allowing them to eat, sleep, gain weight and interact with caregivers. However, the pharmacologic management of NAS remains a challenge. Opioid agonist medications are thought to be the most effective agents in the treatment of neonatal neurobehavioral problems related to in utero opioid exposure. In 2005, the Cochrane Review failed to identify a specific opioid as optimal for the treatment of infants undergoing opioid withdrawal (Osborn et al., 2005). A later review, published in 2011, suggested oral morphine solutions as the mainstay of NAS therapy (Bio et al., 2011).

Later consequences of in utero opioid exposure have also been described in humans. Inattention, hyperactivity, impulsivity and aggression, the major diagnostic criteria of attention deficit hyperactivity disorder (ADHD), are known to persist into adulthood in children born to heroin-dependent mothers or to mothers using methadone during pregnancy (Ornoy et al., 1996). One of the major factors affecting the development of these children is the environment in which they are raised (Ornoy et al., 1996, 2001; Weisglas-Kuperus et al., 1993). Among children born to heroin-dependent mothers raised by adoptive families, hyperactivity was found in a significantly lower percentage than among children exposed to heroin in utero and raised by their biological families.

Nevertheless, the effects of prenatal exposure to drugs on brain development are complex and are modulated by the timing, dose and route of drug exposure (Thompson et al., 2009). Therefore, it is difficult to assess these effects in clinical cohorts, which are beset with problems such as difficulties in documenting use patterns (Jones et al., 2012a). Thus, animal studies are required.

\section{Animal studies}

The immature brain seems to be particularly vulnerable to the actions of opiates (Bashore et al., 1981). Opiates appear to selectively accumulate in the nervous tissues of offspring because of increased permeability of the blood-brain barrier and may affect the development of the central nervous system (CNS) and cause a variety of delays in ontogeny (Peters et al., 1972; Shah and Donald, 1979). Similar to observations in humans, the administration of opiates during fetal development may result in increased intrauterine death, thereby decreasing litter size, in rodents (Fujinaga and Mazze, 1988). Although no teratogenic effects were observed with the chronic administration of morphine in one study, the number of stillbirths and infant mortality increased, and the body growth of the offspring of drug-exposed female rats was stunted (Zagon and McLaughlin, 1977). Fetal exposure to opiates may adversely affect the migration and survival of neurons in rat embryos, thereby leading to an overall inhibition of brain growth and development during this critical period of CNS development (Vathy, 1995; Walhovd et al., 2009). Exposure to opiates prenatally can alter opioid receptor density and distribution. This phenomenon can in turn affect the development of neural connections by delaying or accelerating neural outgrowth. Indeed, heroin exposure in pregnant mice decreased dendrite length and branch numbers in pyramidal neurons in the somatosensory cortex of offspring (Lu et al., 2012).

Later consequences of intrauterine drug exposure have been extensively studied in rodents (Table 1 ). Our own data also support long-term consequences in the offspring of morphine-exposed mothers (from the day of mating until weaning) (Klausz et al., 2011). The persisting somatic changes (Fig. 1) included body and adrenal gland weight decreases, which were a sign of disturbed stress-axis regulation, and altered blood glucose levels (Fig. 3D) (Castellano and Ammassari-Teule, 1984). Changes in motor development and analgesia have also been described (Castellano and Ammassari-Teule, 1984; Eriksson and Ronnback, 1989; Gagin et al., 1996; Robinson and Wallace, 2001). Adult mice that underwent prenatal heroin exposure showed certain signs of impaired short-term spatial memory (Lu et al., 2012). Prenatal morphine exposure may result in enhanced activity and/or sensitivity of the endogenous opiate system, thereby placing the organism at higher risk of opiate drug addiction (Gagin et al., 1997a; Timar et al., 2010; Sobor et al., 2010). Indeed, Ramsey et al. found that prenatal morphine exposure enhanced the reinforcing effects of heroin and cocaine, as measured by self-administration (Ramsey et al., 1993). Prenatal morphine treatment also has an age-dependent effect on seizure susceptibility, which is highly influenced by gonadal hormones, with males being more vulnerable than females to morphine-induced insults during prenatal brain development (Vathy, 2001; Vathy et al., 1998; Slamberova and Vathy, 2000; Schindler et al., 2000; Velisek et al., 1998). As a possible explanation, mu-opioid receptors in seizure-controlling brain structures are sex-specifically altered by prenatal morphine exposure in adult progeny (Slamberova et al., 2002).

There is gender dimorphism in the rodent brain (Vathy, 1995), as prenatal morphine exposure reduces female sexual behavior but does

Table 1

A summary of behavioral consequences of prenatal opioid exposure in rodent models.

\begin{tabular}{|c|c|c|c|}
\hline Behavioral alteration & Tests & Difference & Reference \\
\hline \multirow[t]{2}{*}{ Motor coordination } & Postnatal reflexes & Slightly reduced & Castellano and Ammassari-Teule (1984) \\
\hline & Spontaneous activity & Reduced on PND1, no difference in adult & Castellano and Ammassari-Teule (1984) \\
\hline \multirow[t]{4}{*}{ Anxiety } & Novel environment & Anxiogenic & Byrnes (2005a), Timar et al. (2010) \\
\hline & Open field & No alteration & Hamilton et al. (2005) \\
\hline & Elevated plus maze & Anxiogenic & Byrnes (2005a), Klausz et al. (2011) \\
\hline & Startle response & Enhanced in male, no change in female & Hamilton et al. (2005) \\
\hline \multirow[t]{2}{*}{ Depression } & Forced swim test & Depression-like & McPherson et al. (2007), Klausz et al. (2011) \\
\hline & Saccharin preference & Enhanced & Gagin et al. (1996) \\
\hline \multirow[t]{2}{*}{ Learning } & Symmetrical maze & Faster learning in males but not females & Slamberova et al. (2001a) \\
\hline & Passive avoidance & Impaired & McPherson et al. (2007) \\
\hline Memory & Eight-arm radial maze & Memory decline mostly in females & Slamberova et al. (2001a) \\
\hline \multirow{2}{*}{ Drug sensitivity } & Active and passive avoidance & Enhanced & Castellano and Ammassari-Teule (1984) \\
\hline & Pain & Reduced antinociceptive morphine effect & Timar et al. (2010) \\
\hline \multirow[t]{2}{*}{ Analgesia } & Hot plate & Enhanced sensitivity to morphine & Eriksson and Ronnback (1989), Gagin et al. (1996) \\
\hline & Tail-flick & $\begin{array}{l}\text { Reduced tolerance to antinociceptive effect } \\
\text { of morphine }\end{array}$ & $\begin{array}{l}\text { Gagin et al. (1996), Robinson and Wallace (2001), } \\
\text { Sobor et al. (2010), Timar et al. (2010) }\end{array}$ \\
\hline Sexual behavior & & Inhibition in female, no alteration in male & Vathy et al. (1983, 1985, 1999), Gagin et al. (1997b) \\
\hline Drug seeking & Conditioned place preference & Enhanced & Timar et al. (2010), Sobor et al. (2011) \\
\hline \multirow[t]{2}{*}{ Maternal behavior } & Spontaneous & Decreased & Moura et al. (2010), Sobor et al. (2010, 2011) \\
\hline & Vs. insect hunting & Maternal care decreased & Cruz Ade et al. (2010) \\
\hline
\end{tabular}

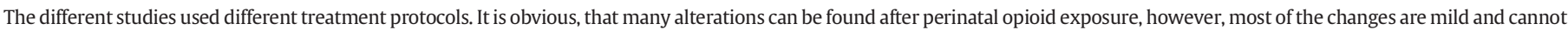
be detected in both sexes. PND - postnatal day. 

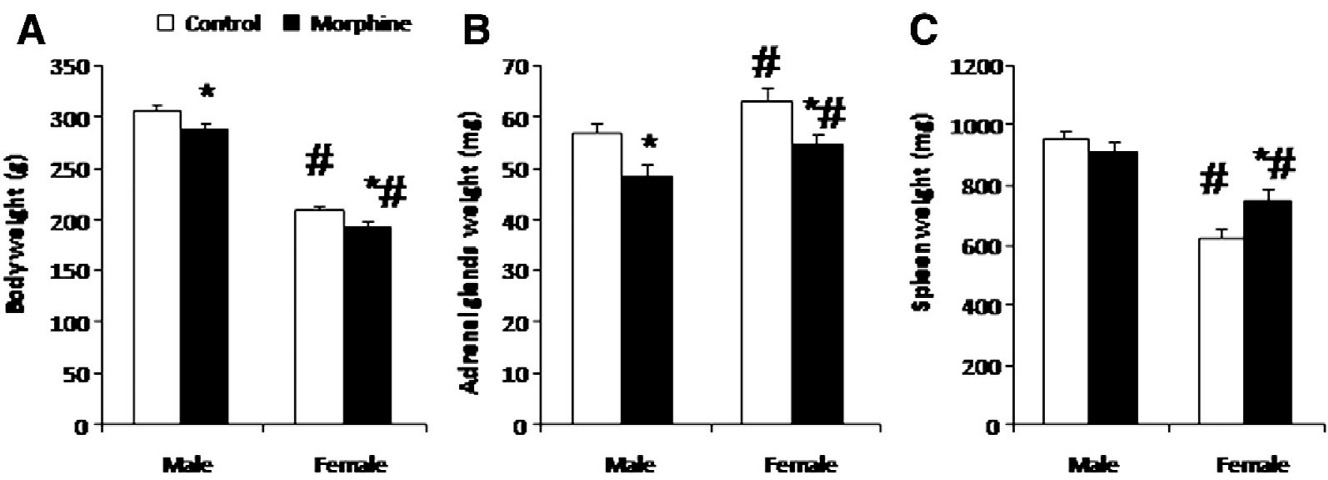

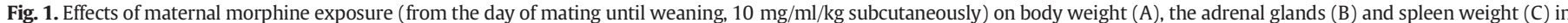

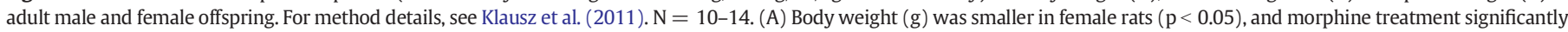

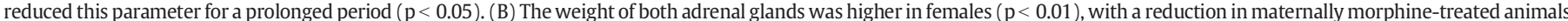

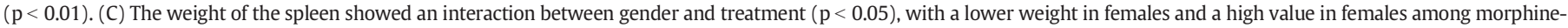
treated animals. ${ }^{*} \mathrm{p}<0.05$ vs. control treatment; $\# \mathrm{p}<0.05$ vs. male.

not have a profound effect on males (Vathy et al., 1985). Adult sexual behavior in female rats is both defeminized and masculinized (Vathy, 1999; Gagin et al., 1997b). The inhibition of female sexual behavior (Vathy et al., 1983) is contrasted by enhanced social play during their juvenile age, most likely due to an influence on motivational and reward systems (Niesink et al., 1996). Our results showed similar dimorphism. The weight of the spleen, reflecting immune function, changed in the opposite manner in males and females (Fig. 1C). As susceptibility to mental illnesses is most likely to change (Fumagalli et al., 2007;
Maccari et al., 2003), we studied mood-relevant behaviors. This examination of anxiety- and depression-like behavior revealed a significant gender-treatment interaction (Fig. 2). In our case, male offspring were more vulnerable to the anxiogenic and depressogenic effects of intrauterine and postnatal morphine treatment than were females subjected to the EPM and the forced swim test (FST) (Klausz et al., 2011). Similarly, Hamilton and coworkers reported an elevated startle response in the male, but not female, offspring of morphine-treated mothers (Hamilton et al., 2005). Additionally, Slamberova et al.

EPM test (anxiety-like behavior)

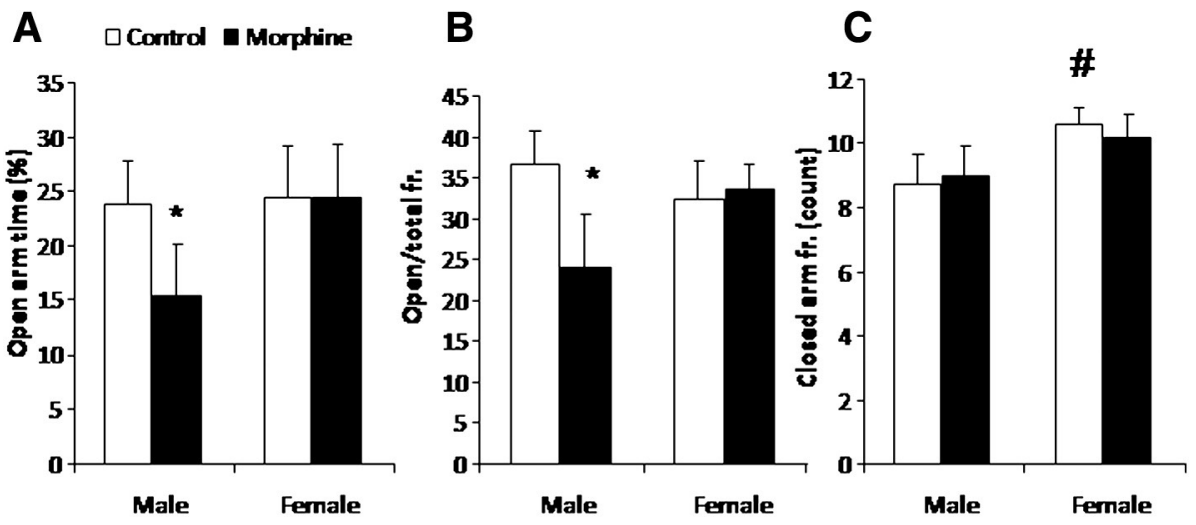

\section{FST (depressive-like behavior)}

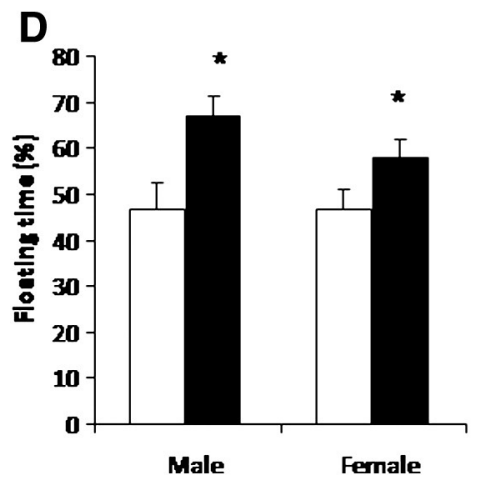

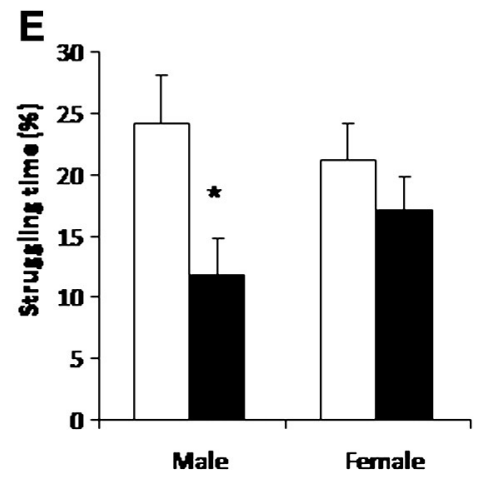

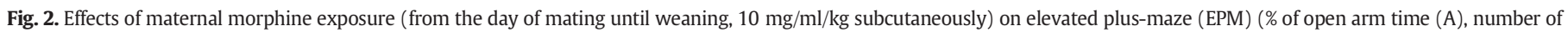

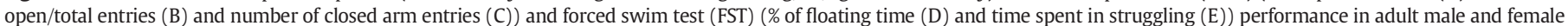

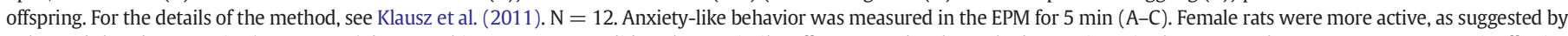

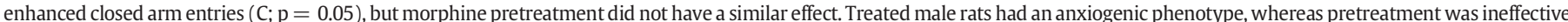

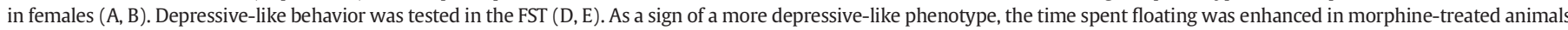

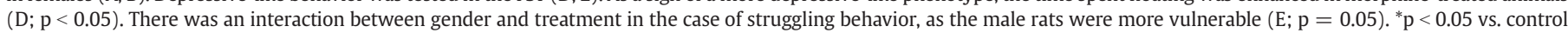
treatment; $\# \mathrm{p}<0.05$ vs. male. 
demonstrated that prenatal morphine exposure differentially altered the performance of adult male and female rats on tasks requiring learning and spatial memory (Slamberova et al., 2001a). Another group reported disturbance in a passive avoidance retention task in females after intrauterine morphine treatment (Degos et al., 2012). We found a significant gender-treatment interaction in the case of stressorinduced blood glucose elevation as well (Fig. 3D).

Dysregulation of the stress axis, and especially alteration in glucocorticoid levels, is a core feature of mood disorders (Joels, 2011). Therefore, it is important to note that prenatal opiate exposure followed by postnatal withdrawal diminished the stress axis response to immunological and social stressors in neonatal rats, whereas in adulthood, an exaggerated response was detected (Hamilton et al., 2005). The adrenocorticotropin (ACTH, the hypophyseal component of the stress response) and corticosterone (a rodent glucocorticoid in the adrenal cortex) responses are dissociated (Rimanoczy et al., 2003; Slamberova et al., 2004). Although there were no differences in basal levels between control animals and intra- and postnatal morphine-treated animals, stressor-induced ACTH elevations were smaller in the opioid-exposed groups. In addition to glucocorticoid regulation, ACTH has many different effects (Zelena and Makara, 2012). Nevertheless, as the end hormones of the axis are glucocorticoids, we are concentrating on these molecules. In our study, resting glucocorticoid levels were elevated in the adult male offspring of morphine-treated dams (among females, the higher basal levels of untreated animals masked any elevation), suggesting chronic stress-like changes (Fig. 3A). FST-induced changes
Basal

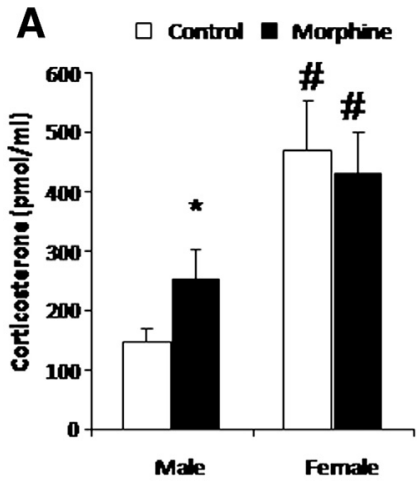

C

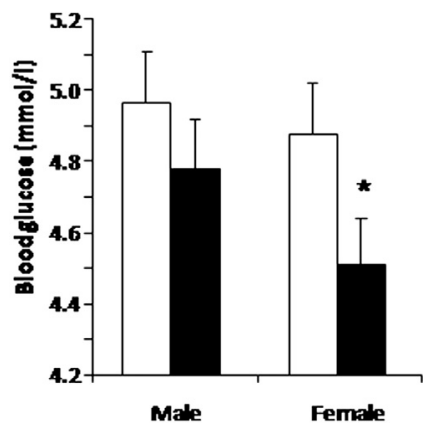

\section{B}

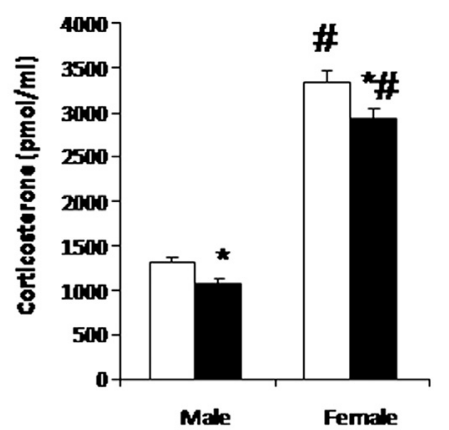

D

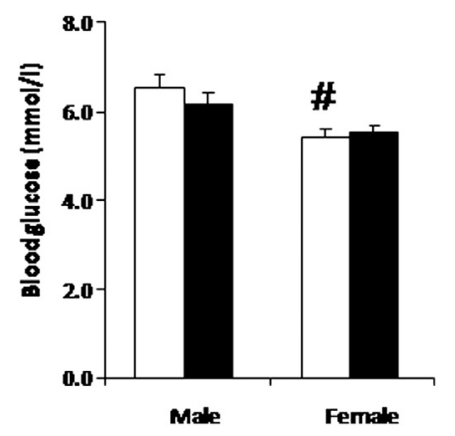

After 5 min FST

Fig. 3. Effects of maternal morphine exposure (from the day of mating until weaning, $10 \mathrm{mg} / \mathrm{ml} / \mathrm{kg}$ subcutaneously) on serum corticosterone and blood glucose changes: $(\mathrm{A}, \mathrm{C})$ basal values and (B, D) after acute stress ( 5 min FST) in adult male and female offspring. For the details of the method, see Klausz et al. (2011). $N=12$. (A) Under basal conditions, female rats had higher corticosterone levels $(p<0.01)$, and morphine pretreatment was able to induce a further increase only in males. (B) At the end of 5 min challenge, females showed much higher levels $(p<0.01)$. However, maternal morphine treatment diminished the elevation in both genders $(\mathrm{p}<0.01)$. (C) Resting blood glucose levels were lower in morphine-treated animals $(p=0.05)$, with more severe changes in females. (D) Stressor exposure induced a smaller increase in females $(\mathrm{p}<0.01){ }^{*} \mathrm{p}<0.05$ vs. control treatment; \#p $<0.05$ vs. male. were smaller in morphine-treated groups of both genders (Fig. 3B). The disturbed stress axis suggested damaged adaptive capability (Klausz et al., 2011). Accordingly, we found smaller stress-related organs (Fig. 1B), hypoactivity of the stress axis (Fig. 3B) and enhanced depression-like behavior during the FST (Fig. 2D, E), and males were at greater risk than females were.

There must be a certain optimum level of opioids, as not only the enhanced activation of their receptors by agonists but also intrauterine and postnatal antagonist exposure (a naltrexone implant is used clinically for people wanting to abstain from opiates and/or alcohol) may induce aversive effects. Although no major adverse neonatal outcomes have been found with respect to birth weight, Apgar score or head circumference (Hulse et al., 2001), long-term follow-up showed reduced locomotor activity, enhanced psychomotor sensitization to morphine and elevated drug-seeking behavior in the adult offspring of naltrexone-treated rat dams (Farid et al., 2012).

\section{Maternal behavior in animals}

Based on human studies (Ornoy et al., 1996), we cannot rule out the possibility that the above-mentioned late consequences were an indirect result of morphine-induced alterations in maternal physiology and/or behavior. Although premating morphine treatment had no effect (see earlier), treatment during lactation can profoundly influence the mother's behavior. It is known that inadequate maternal care results in altered behavioral and endocrine responses to stress in offspring (Levine, 2005; Weaver et al., 2004).

Plasma and brain levels of endogenous opioids increase over the course of pregnancy, peak during parturition and then decline to pre-pregnancy levels during lactation (Petraglia et al., 1985; Wardlaw and Frantz, 1983). These changes in endogenous opioids are consistent with "pregnancy-mediated analgesia", an elevation in the pain threshold (hypoalgesia) during labor and delivery (Gintzler, 1980). Additionally, systemically administered exogenous opiates inhibit maternal behavior in lactating dams (Sobor et al., 2010; Bridges and Grimm, 1982; Slamberova et al., 2001b). Non-sedative doses of morphine disrupt (e.g., increase the latency to retrieve pups) and naloxone restores maternal responsiveness in female rats (Bridges and Grimm, 1982; Haney and Miczek, 1989). During prolonged administration, sensitization also occurs, meaning that maternal behavior may be inhibited by low doses of morphine (e.g., $3 \mathrm{mg} / \mathrm{kg}$ ) that are otherwise ineffective at inducing such inhibition in control lactating rats (in which at least $5 \mathrm{mg} / \mathrm{kg}$ is needed) (Sobor et al., 2010; Miranda-Paiva et al., 2001; Cruz Ade et al., 2010). Moreover, the rewarding potential of morphine increases in treated dams, measured on conditioned place preference (Sobor et al., 2011). Not only is spontaneous maternal care reduced but behavioral selection between pup care and insect hunting also shifted to the latter direction (Cruz Ade et al., 2010). Late pregnancy was particularly sensitive in terms of morphine's effects on maternal behavior (Yim et al., 2006).

Vathy et al. studied the later consequences of disrupted maternal care by morphine-treated mothers for offspring (Vathy et al., 2007). The researchers found that disrupted maternal behavior was more important than prenatal drug exposure itself in rewarding cocaine self-administration in adulthood, especially in female offspring.

However, the late consequences of the in utero morphine exposure of female offspring were opposite to the consequences of the acute maternal effects. In particular, when these offspring became mothers, their active nursing behavior was increased; they were faster in carrying the first pup, returning the first pup to the nest and returning all pups to the nest (Slamberova et al., 2003).

\section{Opioid exposure during labor in human studies}

Reynolds hypothesized that neuraxial analgesia is the worst type of analgesia for babies because of negative maternal changes 
(e.g., maternal hypotension and fever, a prolonged second stage) (Reynolds, 2011). However, the fetal stress response to labor, resulting in a conspicuous catecholamine surge, is beneficial for adaptation to extrauterine life. Nevertheless, pain relief during childbirth is very common, so we have a large amount of human data.

Fentanyl (a synthetic opioid analgesic) is a frequently used, highly lipid soluble drug that would be expected to cross the placenta easily and to rapidly equilibrate between the maternal and the fetal circulation. However, the use of continuous-infusion epidural analgesia with lowdose bupivacaine and fentanyl over periods of up to $15 \mathrm{~h}$ during labor did not result in significant drug accumulation in either the mother or the neonate (Bader et al., 1995). Despite this fact, later consequences of opioid use during labor were present. Babies delivered after their mothers received $>300 \mu \mathrm{g}$ fentanyl during the last $4 \mathrm{~h}$ of labor may be at greater risk of respiratory depression (Kumar and Paes, 2003). Moreover, infants whose mothers received $80 \mu \mathrm{g}$ sufentanil show mild neurobehavioral depression (Capogna et al., 1989). Several types of analgesia given to the mother during labor may interfere with the newborn's spontaneous breast-seeking and breastfeeding behaviors and increase the newborn's temperature and crying (Ransjo-Arvidson et al., 2001).

\section{Newborn exposure}

\section{Via the mother}

\section{Human data}

Milk production is a mammalian characteristic and is of particular importance for humans. In addition to their well-known nutritive role, milk constituents can carry specific information (Teschemacher et al., 1997). Thus, a number of milk protein fragments have been shown to behave as opioid receptor ligands. Most of these fragments have agonistic properties, and beta-casomorphins have known functional significance (Teschemacher and Koch, 1991). These peptides are implicated in a number of medical conditions, including diabetes, heart disease and symptoms of autism and schizophrenia, although the currently available data are inadequate to guide treatment recommendations (e.g., to eliminate the origin of casomorphin, casein, from the diet) (Christison and Ivany, 2006).

Recreational use of opioids exclusively during lactation is rare. However, maternal painkillers may have an effect on offspring. It is well documented that one of the overlooked effects of opiate use is an opiate-mediated elevation in the secretion of prolactin (Byrnes, 2005b). This elevation may lead to better milk production, which may partly compensate for harmful outcomes. In line with this observation, in one study, post-cesarean analgesia with epidural morphine had a relatively positive effect on offspring, who were more alert and oriented to animate human cues (Wittels et al., 1997).

\section{Animal studies}

Despite the possible positive effects in humans, Timar et al. found that in rats postnatal exposure to morphine through maternal milk resulted in slower weight gain and in males impaired habituation to a new environment (Timar et al., 2010). Moreover, the female offspring of morphinetreated lactating rat mothers (postnatal days (PNDs) 1-21) failed in a passive avoidance retention task (Nasiraei-Moghadam et al., 2013).

\section{Direct infant exposure}

\section{Therapeutic usage in humans}

Both neonates and infants are able to mount a graded hormonal stress response to surgical interventions. Adequate intra- and postoperative analgesia not only modifies the stress response but also has been shown to reduce morbidity and mortality (Lonnqvist and Morton, 2005). Repetitive untreated pain and distress may impair the premature brain and have short- and long-term negative consequences (Duhrsen et al., 2013; Walker, 2014). For example, the effects of neonatal inflammatory pain resulted in decreased locomotor activity in adult rats, and this effect was reduced by morphine pretreatment (Bhutta et al., 2001). Therefore, pain management is increasingly recognized as an integral part of the effective management of vulnerable babies in the neonatal intensive care unit (NICU) (Walker, 2014; Hall, 2012). Beyond the most common non-pharmacologic techniques (sucking, maternal contact and massage), the drugs used to treat neonatal pain include opiates.

Nevertheless, opioid use poses a certain risk. The neuraxial administration of opioids may induce respiratory depression and increase the number of secondary medical interventions (due to postoperative nausea and vomiting, urinary retention and pruritus and decreased recovery of gastrointestinal function) (Hall, 2012; Lonnqvist et al., 2002). Morphine premedication for intubation leads to prolonged $(24 \mathrm{~h}$ ) electroencephalogram (EEG) depression, so this treatment is not recommended for short interventions (Norman et al., 2013). A high dose of opioids may induce EEG spikes, although behavioral convulsions are only rarely detected (van Praag and Frenk, 1992). Additionally, placebo-controlled trials in ventilated neonates found that fentanyl reduced stress hormones (catecholamines and glucocorticoids), episodes of hypoxia and behavioral stress scores but increased ventilation requirements (Anand and Hall, 2006). Moreover, morphine seems to provide adequate sedation and analgesia during hypothermia for the treatment of neonatal asphyxial encephalopathy (Roka et al., 2008). Taken together, several studies and reviews (e.g., Cochrane Reviews) have concluded that opiates should be used selectively in NICU newborns (Bellu et al., 2010).

\section{Experimental conditions in rodents}

Postnatal morphine administration may have negative effects on somatic development (including body growth and eye and vaginal opening development) (Zimmerman et al., 1977) and on neuronal growth in the developing animal (Hammer et al., 1989). Rozisky et al. observed that morphine treatment in early life in newborn male rats modulates brain-derived neurotrophic factor (BDNF) levels in the hippocampus (Rozisky et al., 2013). These changes may underlie behavioral alterations. Indeed, early postnatal exposure to morphine significantly decreased the ultrasonic vocalization of rat pups removed from their nest, serving as a marker of behavioral development (Cuomo et al., 1988). Moreover, repeated neonatal morphine injections in rats impaired passive avoidance learning and altered FST behavior in adulthood (McPherson et al., 2007).

Intraplantar formalin-induced pain reactions were reduced by acute morphine treatment in neonates (Abbott and Guy, 1995). However, when the postnatal morphine administration was followed by 4 days of abstinence, the pain reaction increased significantly (Zissen et al., 2006). Similarly, antinociceptive tolerance to morphine administration developed, as measured by a hot plate test (Bajic et al., 2013). In these cases, brain region-specific apoptosis occurred in unaffected glial cells, serving as a possible background mechanism (Bajic et al., 2013).

Controversially, the postnatal treatment of male rats with morphine reduced the development of pentylenetetrazol (PTZ)-induced seizures and the mortality rate in adulthood, possibly through the activation of GABAergic neurons in the hippocampus (Saboory et al., 2014). This effect was very similar to the consequences of prenatal morphine treatment, with decreased susceptibility to GABA-regulated seizures (Vathy, 2001). Additionally, morphine treatment may protect the developing brain from severe pain-induced pathological changes, although only under certain conditions (Duhrsen et al., 2013). Postnatal morphine treatment results in enhanced tail flick latency and a reduced ethanol preference, suggesting an additional positive impact (Duhrsen et al., 2013).

\section{Conclusions}

The most common perinatal usage of opioids is for medical purposes, mostly in the form of a single or short-term treatment, and 
the main reason is to relieve pain. There is compelling evidence that an adverse intrauterine and postnatal environment can affect offspring's development and potentially lead to various learning, behavioral and mood disorders and to complex diseases, such as obesity and cardiovascular conditions, later in life (Schuurmans and Kurrasch, 2013; Rinaudo and Lamb, 2008; Viltart and Vanbesien-Mailliot, 2007). In particular, susceptibility to mental illnesses can increase (Fumagalli et al., 2007; Maccari et al., 2003). It is clear that repetitive painful experiences, such as randomly occurring invasive procedures and handling during neonatal intensive care, can permanently alter neuronal and synaptic organization and therefore later behavior (Anand, 2000). At the same time, analgesic drugs can be harmful, as morphine has been found to increase apoptosis in human fetal microglia and neurons (Hu et al., 2002). Whereas the short-term consequences of prolonged analgesic therapy in human neonates are well-known (tolerance, withdrawal and ventilator dependency), their long-term consequences are relatively unknown; animal studies suggest negative outcomes. Therefore, riskbenefit ratios should always be taken into consideration when pain relief is required in pregnant women or in neonates.

Recreational use of opioids can also alter many aspects of perinatal life; even the probability of conception may be disturbed. Intrauterine opioid exposure has many toxic effects (see above), leading to poor pregnancy outcomes, including underdevelopment, but it is believed that later negative consequences (Table 1) are more related to negative environmental factors (Ornoy et al., 1996; Weisglas-Kuperus et al., 1993). One of the crucial components is the disturbance of maternal care, which changes profoundly in substance-using mothers. Interventions will need to address the factors surrounding drug use to greatly improve neonatal outcomes (e.g., social circumstances, poor nutrition, stress, infections) (Schempf, 2007). Nevertheless, there is a certain optimum level of opioids, as not only opioid agonists but also antagonists have been shown to have long-term negative impacts (Farid et al., 2012). In dependent mothers, pre- and postnatal care initiation by society has special importance, and controlled treatment with a synthetic opioid (e.g., methadone or buprenorphine) could be beneficial (Kandall et al., 1999).

It is important to close the gap between scientific knowledge and societal programs for at-risk populations (Thompson et al., 2009; Walhovd et al., 2009). More emphasis should be given to disseminating scientific knowledge, enlightenment and prevention.

\section{Conflict of interest statement}

We disclose no possible conflict of interest in the conduct and reporting of research (e.g., financial interests in a test or procedure, funding by pharmaceutical companies for drug research).

\section{Acknowledgments}

Our work was supported by the grant OTKA NN71629.

\section{References}

Abbott FV, Guy ER. Effects of morphine, pentobarbital and amphetamine on formalininduced behaviours in infant rats: sedation versus specific suppression of pain. Pain 1995;62(3):303-12.

Anand KJ. Effects of perinatal pain and stress. Prog Brain Res 2000;122:117-29.

Anand KJ, Hall RW. Pharmacological therapy for analgesia and sedation in the newborn Arch Dis Child Fetal Neonatal Ed 2006;91(6):F448-53.

Bader AM, et al. Maternal and neonatal fentanyl and bupivacaine concentrations after epidural infusion during labor. Anesth Analg 1995;81(4):829-32.

Bajic D, Commons KG, Soriano SG. Morphine-enhanced apoptosis in selective brain regions of neonatal rats. Int J Dev Neurosci 2013;31(4):258-66.

Bashore RA, et al. Heroin addiction and pregnancy. West J Med 1981;134(6):506-14

Bellu R, de Waal K, Zanini R. Opioids for neonates receiving mechanical ventilation: a systematic review and meta-analysis. Arch Dis Child Fetal Neonatal Ed 2010;95(4): F241-51.

Bhutta AT, et al. Interactions of inflammatory pain and morphine in infant rats: long-term behavioral effects. Physiol Behav 2001;73(1-2):51-8.

Bhuvaneswar CG, et al. Cocaine and opioid use during pregnancy: prevalence and management. Prim Care Companion J Clin Psychiatry 2008;10(1):59-65.
Bio LL, Siu A, Poon CY. Update on the pharmacologic management of neonatal abstinence syndrome. J Perinatol 2011;31(11):692-701.

Bridges RS, Grimm CT. Reversal of morphine disruption of maternal behavior by concurrent treatment with the opiate antagonist naloxone. Science 1982;218(4568):166-8.

Byrnes EM. Transgenerational consequences of adolescent morphine exposure in female rats: effects on anxiety-like behaviors and morphine sensitization in adult offspring. Psychopharmacology (Berlin) 2005a:182(4):537-44.

Byrnes EM. Chronic morphine exposure during puberty decreases postpartum prolactin secretion in adult female rats. Pharmacol Biochem Behav 2005b;80(3):445-51.

Capogna G, Celleno D, Tomassetti M. Maternal analgesia and neonatal effects of epidural sufentanil for cesarean section. Reg Anesth 1989;14(6):282-7.

Castellano C, Ammassari-Teule M. Prenatal exposure to morphine in mice: enhanced responsiveness to morphine and stress. Pharmacol Biochem Behav 1984;21(1):103-8.

Christison GW, Ivany K. Elimination diets in autism spectrum disorders: any wheat amidst the chaff? J Dev Behav Pediatr 2006;27(2 Suppl):S162-71.

Cruz Ade M, et al. Morphine treatment during pregnancy modulates behavioral selection in lactating rats. Physiol Behav 2010;101(1):40-4.

Cuomo V, et al. Ultrasonic vocalization in rat pups as a marker of behavioral development: an investigation of the effects of drugs influencing brain opioid system. Neurotoxicol Teratol 1988;10(5):465-9.

Degos V, et al. Elderly age as a prognostic marker of 1 -year poor outcome for subarachnoid hemorrhage patients through its interaction with admission hydrocephalus. Anesthesiology 2012;117(6):1289-99.

Duhrsen L, et al. Effects of repetitive exposure to pain and morphine treatment on the neonatal rat brain. Neonatology 2013;103(1):35-43.

Eriksson PS, Ronnback L. Effects of prenatal morphine treatment of rats on mortality, bodyweight and analgesic response in the offspring. Drug Alcohol Depend 1989; 24(3):187-94.

Farid WO, et al. Maternally administered sustained-release naltrexone in rats affects offspring neurochemistry and behaviour in adulthood. PLoS One 2012; 7(12):e52812.

Fujinaga M, Mazze RI. Teratogenic and postnatal developmental studies of morphine in Sprague-Dawley rats. Teratology 1988;38(5):401-10.

Fumagalli F, et al. Stress during development: Impact on neuroplasticity and relevance to psychopathology. Prog Neurobiol 2007:81(4):197-217.

Gagin R, Cohen E, Shavit Y. Prenatal exposure to morphine alters analgesic responses and preference for sweet solutions in adult rats. Pharmacol Biochem Behav 1996;55(4): 629-34.

Gagin R, et al. Prenatal morphine enhances morphine-conditioned place preference in adult rats. Pharmacol Biochem Behav 1997a;58(2):525-8.

Gagin R, Cohen E, Shavit Y. Prenatal exposure to morphine feminizes male sexual behavior in the adult rat. Pharmacol Biochem Behav 1997b;58(2):345-8.

Gintzler AR. Endorphin-mediated increases in pain threshold during pregnancy. Science 1980;210(4466):193-5

Hall RW. Anesthesia and analgesia in the NICU. Clin Perinatol 2012;39(1):239-54.

Hamilton KL, et al. HPA axis dysregulation following prenatal opiate exposure and postnatal withdrawal. Neurotoxicol Teratol 2005;27(1):95-103.

Hammer Jr RP, Ricalde AA, Seatriz JV. Effects of opiates on brain development. Neurotoxicology 1989;10(3):475-83.

Haney M, Miczek KA. Morphine effects on maternal aggression, pup care and analgesia in mice. Psychopharmacology (Berlin) 1989;98(1):68-74.

Holbrook A, Kaltenbach K. Gender and NAS: does sex matter? Drug Alcohol Depend 2010; 112(1-2):156-9.

Hu S, et al. Morphine induces apoptosis of human microglia and neurons. Neuropharmacology 2002;42(6):829-36.

Hulse GK, et al. The relationship between maternal use of heroin and methadone and infant birth weight. Addiction 1997;92(11):1571-9.

Hulse GK, et al. Assessing the relationship between maternal opiate use and neonatal mortality. Addiction 1998;93(7):1033-42.

Hulse GK, et al. Obstetric and neonatal outcomes associated with maternal naltrexone exposure. Aust N Z J Obstet Gynaecol 2001;41(4):424-8.

Jansson LM, Velez M, Harrow C. The opioid-exposed newborn: assessment and pharmacologic management. J Opioid Manag 2009;5(1):47-55.

Joels M. Impact of glucocorticoids on brain function: relevance for mood disorders. Psychoneuroendocrinology 2011;36(3):406-14.

Johnson K, Gerada C, Greenough A. Substance misuse during pregnancy. Br J Psychiatry 2003;183:187-9.

Johnson NL, et al. Adolescent opiate exposure in the female rat induces subtle alterations in maternal care and transgenerational effects on play behavior. Front Psychiatry $2011 \cdot 2 \cdot 29$.

Jones HE, et al. Maternal Opioid Treatment: Human Experimental Research (MOTHER)approach, issues and lessons learned. Addiction 2012a;107(Suppl. 1):28-35.

Jones HE, et al. Buprenorphine treatment of opioid-dependent pregnant women: a comprehensive review. Addiction 2012b;107(Suppl. 1):5-27.

Kaltenbach KA. Exposure to opiates: behavioral outcomes in preschool and school-age children. NIDA Res Monogr 1996;164:230-41.

Kandall SR, et al. Differential effects of heroin and methadone on birth weights. Addict Dis 1975;2(1-2):347-55.

Kandall SR, et al. The methadone-maintained pregnancy. Clin Perinatol 1999;26(1): 173-83.

Kapp C. Swiss debate whether to legalise cannabis. Alcohol and tobacco pose far greater danger, say advocates of cannabis legalisation. Lancet 2003;362(9388):970.

Klausz B, et al. Changes in adaptability following perinatal morphine exposure in juvenile and adult rats. Eur J Pharmacol 2011;654(2):166-72.

Kumar M, Paes B. Epidural opioid analgesia and neonatal respiratory depression. J Perinatol 2003;23(5):425-7. 
Lam SK, et al. Narcotic addiction in pregnancy with adverse maternal and perinatal outcome. Aust N Z J Obstet Gynaecol 1992;32(3):216-21.

Levine S. Developmental determinants of sensitivity and resistance to stress. Psychoneuroendocrinology 2005;30(10):939-46.

Lonnqvist PA, Morton NS. Postoperative analgesia in infants and children. Br J Anaesth 2005;95(1):59-68

Lonnqvist PA, Ivani G, Moriarty T. Use of caudal-epidural opioids in children: still state of the art or the beginning of the end? Paediatr Anaesth 2002:12(9):747-9.

Lu R, et al. Effects of prenatal cocaine and heroin exposure on neuronal dendrite morphogenesis and spatial recognition memory in mice. Neurosci Lett 2012; 522(2):128-33.

Maccari S, et al. Prenatal stress and long-term consequences: implications of glucocorticoid hormones. Neurosci Biobehav Rev 2003;27(1-2):119-27.

McPherson RJ, et al. A new model of neonatal stress which produces lasting neurobehavioral effects in adult rats. Neonatology 2007:92(1):33-41.

Miranda-Paiva CM, et al. Morphine pretreatment increases opioid inhibitory effects on maternal behavior. Brain Res Bull 2001;55(4):501-5.

Moura LM, et al. Morphine infusions into the rostrolateral periaqueductal gray affect maternal behaviors. Braz J Med Biol Res 2010;43(9):899-905

Nasiraei-Moghadam S, et al. Reversal of prenatal morphine exposure-induced memory deficit in male but not female rats. J Mol Neurosci 2013;50(1):58-69.

Niesink RJ, Vanderschuren LJ, van Ree JM. Social play in juvenile rats after in utero exposure to morphine. Neurotoxicology 1996;17(3-4):905-12.

Norman E, et al. Premedication for intubation with morphine causes prolonged depression of electrocortical background activity in preterm infants. Pediatr Res 2013;73(1):87-94

Ornoy A, et al. The developmental outcome of children born to heroin-dependent mothers, raised at home or adopted. Child Abuse Negl 1996;20(5):385-96.

Ornoy A, et al. Developmental outcome of school-age children born to mothers with heroin dependency: importance of environmental factors. Dev Med Child Neurol 2001;43(10):668-75.

Osborn DA, Cole MJ, Jeffrey HE. Opiate treatment for opiate withdrawal in newborn infants. John Wiley \& Sons, Ltd.; 2005

Peters MA, Turnbow M, Buchenauer D. The distribution of methadone in the nonpregnant, pregnant and fetal rat after acute methadone treatment. J Pharmacol Exp Ther 1972;181(2):273-8.

Petraglia F, et al. Opioid peptides of the pituitary and hypothalamus: changes in pregnant and lactating rats. J Endocrinol 1985;105(2):239-45.

Ramsey NF, Niesink RJ, Van Ree JM. Prenatal exposure to morphine enhances cocaine and heroin self-administration in drug-naive rats. Drug Alcohol Depend 1993;33(1):41-51.

Ransjo-Arvidson AB, et al. Maternal analgesia during labor disturbs newborn behavior: effects on breastfeeding, temperature, and crying. Birth 2001;28(1):5-12.

Reynolds F. Labour analgesia and the baby: good news is no news. Int J Obstet Anesth 2011;20(1):38-50

Rimanoczy A, et al. Adrenocorticotropin stress response but not glucocorticoid-negative feedback is altered by prenatal morphine exposure in adult male rats. Neuroendocrinology 2003:78(6):312-20.

Rinaudo PF, Lamb J. Fetal origins of perinatal morbidity and/or adult disease. Semin Reprod Med 2008;26(5):436-45.

Robinson SE, Wallace MJ. Effect of perinatal buprenorphine exposure on development in the rat. J Pharmacol Exp Ther 2001;298(2):797-804.

Rockville MD. 2010 National Survey on Drug Use and Health: summary of national findings. Substance Abuse and Mental Health Services Administration; 2011. p. SMA 11-SMA 4658.

Rockville MD. Results from the 2011 National Survey on Drug Use and Health: summary of national findings. Substance Abuse and Mental Health Services Administration, H-44; 2012. p. SMA 12-SMA 4713.

Roka A, et al. Elevated morphine concentrations in neonates treated with morphine and prolonged hypothermia for hypoxic ischemic encephalopathy. Pediatrics 2008; 121(4):e844-9.

Rosenfeld GC, Loose DS. Pharmacology. Lippincott Williams \& Wilkins; 2007.

Rozisky JR, et al. Neonatal morphine administration leads to changes in hippocampal BDNF levels and antioxidant enzyme activity in the adult life of rats. Neurochem Res 2013;38(3):494-503.

Saboory E, et al. The long-term effects of neonatal morphine administration on the pentylenetetrazol seizure model in rats: the role of hippocampal cholinergic receptors in adulthood. Dev Psychobiol 2014;56(3):498-509.

Schempf AH. Illicit drug use and neonatal outcomes: a critical review. Obstet Gynecol Surv 2007;62(11):749-57.

Schindler CJ, et al. Prenatal morphine exposure alters susceptibility to bicuculline seizures in a sex- and age-specific manner. Brain Res Dev Brain Res 2000;121(1):119-22.

Schuurmans C, Kurrasch DM. Neurodevelopmental consequences of maternal distress: what do we really know? Clin Genet 2013;83(2):108-17.

Shah NS, Donald AG. Pharmacological effects and metabolic fate of levo-methadone during postnatal development in rat. J Pharmacol Exp Ther 1979;208(3):491-7.

Slamberova R, Vathy I. Estrogen differentially alters NMDA- and kainate-induced seizures in prenatally morphine- and saline-exposed adult female rats. Pharmacol Biochem Behav 2000;67(3):501-5.

Slamberova R, et al. Prenatal morphine exposure differentially alters learning and memory in male and female rats. Physiol Behav 2001a;73(1-2):93-103.

Slamberova R, Szilagyi B, Vathy I. Repeated morphine administration during pregnancy attenuates maternal behavior. Psychoneuroendocrinology 2001b;26(6):565-76.

Slamberova R, et al. Mu-opioid receptors in seizure-controlling brain structures are altered by prenatal morphine exposure and by male and female gonadal steroids in adult rats. Brain Res Bull 2002;58(4):391-400.
Slamberova R, Bar N, Vathy I. Long-term effects of prenatal morphine exposure on maternal behaviors differ from the effects of direct chronic morphine treatment Dev Psychobiol 2003;43(4):281-9.

Slamberova R, et al. Hypothalamo-pituitary-adrenal axis-regulated stress response and negative feedback sensitivity is altered by prenatal morphine exposure in adult female rats. Neuroendocrinology 2004;80(3):192-200.

Slamberova R, Riley MA, Vathy I. Cross-generational effect of prenatal morphine exposure on neurobehavioral development of rat pups. Physiol Res 2005:54(6):655-60.

Smith JC, et al. Isoflurane with morphine is a suitable anaesthetic regimen for embryo transfer in the production of transgenic rats. Lab Anim 2004;38(1):38-43.

Sobor M, et al. Does the effect of morphine challenge change on maternal behaviour of dams chronically treated with morphine during gestation and further on during lactation? Pharmacol Biochem Behav 2010;95(3):367-74.

Sobor M, et al. Effects of opioid agonist and antagonist in dams exposed to morphine during the perinatal period. Brain Res Bull 2011;84(1):53-60.

Strauss ME, et al. Methadone maintenance during pregnancy: pregnancy, birth, and neonate characteristics. Am J Obstet Gynecol 1974;120(7):895-900.

Teschemacher H, Koch G. Opioids in the milk. Endocr Regul 1991;25(3):147-50.

Teschemacher H, Koch G, Brantl V. Milk protein-derived opioid receptor ligands. Biopolymers 1997;43(2):99-117.

Thompson BL, Levitt P, Stanwood GD. Prenatal exposure to drugs: effects on brain development and implications for policy and education. Nat Rev Neurosci 2009; 10(4):303-12

Timar J, et al. Peri, pre and postnatal morphine exposure: exposure-induced effects and sex differences in the behavioural consequences in rat offspring. Behav Pharmacol 2010:21(1):58-68

Twigt JM, et al. The preconception diet is associated with the chance of ongoing pregnancy in women undergoing IVF/ICSI treatment. Hum Reprod 2012;27(8): 2526-31.

van Praag H, Frenk H. The effects of systemic morphine on behavior and EEG in newborn rats. Brain Res Dev Brain Res 1992;67(1):19-26.

Vathy I. Effects of prenatal morphine and cocaine on postnatal behaviors and brain neurotransmitters. NIDA Res Monogr 1995;158:88-114.

Vathy I. Effects of prenatal morphine exposure on rat heterotypical sexual behavior. Physiol Behav 1999;66(4):667-71.

Vathy I. Prenatal morphine exposure induces age- and sex-dependent changes in seizure susceptibility. Prog Neuropsychopharmacol Biol Psychiatry 2001;25(6):1203-26.

Vathy IU, et al. Effects of prenatal exposure to morphine sulfate on reproductive function of female rats. Pharmacol Biochem Behav 1983;19(5):777-80.

Vathy IU, Etgen AM, Barfield RJ. Effects of prenatal exposure to morphine on the development of sexual behavior in rats. Pharmacol Biochem Behav 1985;22(2):227-32.

Vathy I, Veliskova J, Moshe SL. Prenatal morphine exposure induces age-related changes in seizure susceptibility in male rats. Pharmacol Biochem Behav 1998;60(3):635-8.

Vathy I, Slamberova R, Liu X. Foster mother care but not prenatal morphine exposure enhances cocaine self-administration in young adult male and female rats. Dev Psychobiol 2007;49(5):463-73.

Velisek L, et al. Prenatal morphine exposure alters ovarian steroid hormonal regulation of seizure susceptibility. Brain Res 1998;796(1-2):247-56.

Viltart O, Vanbesien-Mailliot CC. Impact of prenatal stress on neuroendocrine programming. ScientificWorldJournal 2007:7:1493-537.

Walhovd KB, et al. Effects of prenatal opiate exposure on brain development-a call for attention. Nat Rev Neurosci 2009;10(5):390

Walker SM. Neonatal pain. Paediatr Anaesth 2014;24(1):39-48.

Wardlaw SL, Frantz AG. Brain beta-endorphin during pregnancy, parturition, and the postpartum period. Endocrinology 1983;113(5):1664-8.

Weaver IC, et al. Epigenetic programming by maternal behavior. Nat Neurosci 2004;7(8): $847-54$.

Weber $\mathrm{AE}$, et al. High pregnancy rates and reproductive health indicators among female injection-drug users in Vancouver, Canada. Eur J Contracept Reprod Health Care 2003;8(1):52-8

Weisglas-Kuperus N, et al. Effects of biological and social factors on the cognitive development of very low birth weight children. Pediatrics 1993;92(5):658-65.

Wittels B, et al. Postcesarean analgesia with both epidural morphine and intravenous patient-controlled analgesia: neurobehavioral outcomes among nursing neonates. Anesth Analg 1997;85(3):600-6.

Yanai J, et al. Functional changes after prenatal opiate exposure related to opiate receptors' regulated alterations in cholinergic innervation. Int J Neuropsychopharmaco 2003:6(3):253-65.

Yim AJ, et al. A comparative study of morphine treatment regimen prior to mating and during late pregnancy. Brain Res Bull 2006;68(5):384-91.

Zagon IS, McLaughlin PJ. Effects of chronic morphine administration on pregnant rats and their offspring. Pharmacology 1977;15(4):302-10.

Zelena D, Makara GB. The role of adrenocorticotropin beyond the glucocorticoid horizon Advances in medicine and biology, 43(III.). Nova Publisher; 2012. p. 109-38.

Zimmerman E, Sonderegger T, Bromley B. Development and adult pituitary-adrena function in female rats injected with morphine during different postnatal periods. Life Sci 1977;20(4):639-46.

Zissen $\mathrm{MH}$, et al. Acute and chronic morphine alters formalin pain in neonatal rats. Neurosci Lett 2006;400(1-2):154-7. 